Volume 8. No. 10, October 2020

International Journal of Emerging Trends in Engineering Research

Available Online at http://www.warse.org/IJETER/static/pdf/file/ijeter208102020.pdf

https://doi.org/10.30534/ijeter/2020/208102020

\title{
Design Microswitch Based on a Compliant Bistable Mechanism with Triple Stepped Beam Structure
}

\author{
Ngoc Tran Le ${ }^{1}$, Duy Tuan Le ${ }^{2}$ \\ ${ }^{1}$ Faculty of Mechanical Engineering, Industrial University Of Ho Chi Minh City, Ho Chi Minh City, Vietnam, \\ lengoctran@iuh.edu.vn \\ ${ }^{2}$ Faculty of Mechanical Engineering, Industrial University Of Ho Chi Minh City, Ho Chi Minh City, Vietnam, \\ Corresponding author email: leduytuan@iuh.edu.vn
}

\begin{abstract}
A new design of a bistable microswitch based on a triple stepped beam structure is presented. The device is suitable for complementary metal-oxide-semiconductor (CMOS) compatible microelectromechanical system (MEMS) processes. The design of the device is based on Taiwan Semiconductor Manufacturing Company (TSMC) two-poly four-metal $(2 P 4 M)$ process. Finite element analyses are utilized in design of the bistable micro switch. Switching between the bistable states is accomplished electrostatically. The device requires a very low input force, nearly $0.85 \mathrm{mN}$ and $0.23 \mathrm{mN}$ for on and off switch operation, respectively.
\end{abstract}

Key words : Bistable mechanism, stepped beam, electrostatic, micro switch.

\section{INTRODUCTION}

Microswitches are the miniature devices, have two stages in operation, suspend and persist the current pass through the conductors. Microswitches help reduce the size of the MEMS devices, save power and increase speed in some unique chips. They have various utilizations in medical [1], sensors [2-4], optic [5], valve [6], etc. Many designs of microswitch have been studied with different fabrication technology. Yang et al. [7] introduced the multilayer structure that combines the proof mass and conjoined snake springs, which encourage the contact effect and protect shock damage in operation. An improvement of contact behavior, proposed by Xu et al. [8], combine the movable and stationary electrode in the two-level structure. Employing the nonlinear springs in microswitch is investigated by Wen and Zhao [9], allow developing many switches with high accuracy. Despite this, most of them are work in an in-plane direction.

In order to control the microswitches, many effects are employed. Several microswitches use vibration to drive the microswitches, especially in the acceleration applications [10]. Piezoelectric is further employed in actuating the microswitches. A simple piezoelectrical cantilever beam is introduced by Tommasi et al. [11]. A development of cantilever structure formed on piezoelectric and thin film is demonstrated by Chen et al. [12], the device driven by piezoelectric with many dimensions so that the investigation of contact force is achieved. Mao et al. [13] reported the utilization electrothermal effect in the microswitch, which is suitable for the telecommunication system. Magnetic force and electrostatic are also applied in driving the microswitches $[14,15]$.

Bistable mechanisms (BMs) are gaining attention in MEMS applications. An outstanding advantage of BMs is that no power is required to keep the mechanism in either of its bistable positions [16]. Electrostatic means are attractive because of the high energy densities, large forces available in microscale and process compatibility. Various approaches for micromechanical bistable switches have been published [17-20].

Several bistable mechanisms applied for microswitches are reported. Kim and Han fabricated the out-of-plane compliant bistable mechanism with the microinjection molding technology [21]. The V-shaped beams are applied in the design. Therefore, the mechanism made of plastic, not suitable for many MEMS devices. A multimorphs structure introduced by Zhou and Xie [22], the out-of-plane bistable mechanism, is driven by the electrothermal actuator gives the massive deflection in operation. Khoury et al. [23] developed the out-of-plane bistable mechanism with an electrothermal actuator. The devices operate with two stages: the first stage is the in-plane motion and the second stage is the out-of-plane motion. The in-plane motion latches the out-of-plane motion in the second stable location. A simple structure of a bistable out-of-plane switch is introduced by $\mathrm{Yu}$ et al. [24], the mechanism is a beam with two springs, the joule heating effect controls the movement of the beam. Based on the magnetic effect, Miao et al. [25] presented a bistable microswitch work on electromagnetic force. The structure is fabricated on a single wafer with snake springs and permanent magnets. 
Ngoc Tran Le et al., International Journal of Emerging Trends in Engineering Research, 8(10), October 2020, 6746 - 6749

In this research, a development of the triple stepped structure is compatible with TSMC $2 \mathrm{P} 4 \mathrm{M}$ process. Bistable switch based on a triple stepped beam structure is proposed. The electrostatic effect is employed to create the external force in bistable mechanism. Finite element analyses are carryout out for design and analysis of the device. Mechanical behaviors of the beam structure are characterized.

\section{DESIGN}

A schematic of bistable switch based on a triple stepped beam structure is shown in figure 1(a). The beam structure is electrically conductive. Initially, the beam structure is in its first stable equilibrium position. When a voltage difference is applied between the beam structure and the bottom electrode (see figure 1(a)), the stepped beam is moved downward towards the conduction path by the presence of the electrostatic force F. The contact position is located between the unstable equilibrium position and the second stable equilibrium position of the beam structure to ensure electrical conduction of the conduction path. The switch stays at the contact location even when the voltage bias is removed (see Figure 1(b)). When a voltage bias input is applied between the beam and the top electrode, the beam moves upward and returns to its initial state, off state (see Fig. 1(c)).
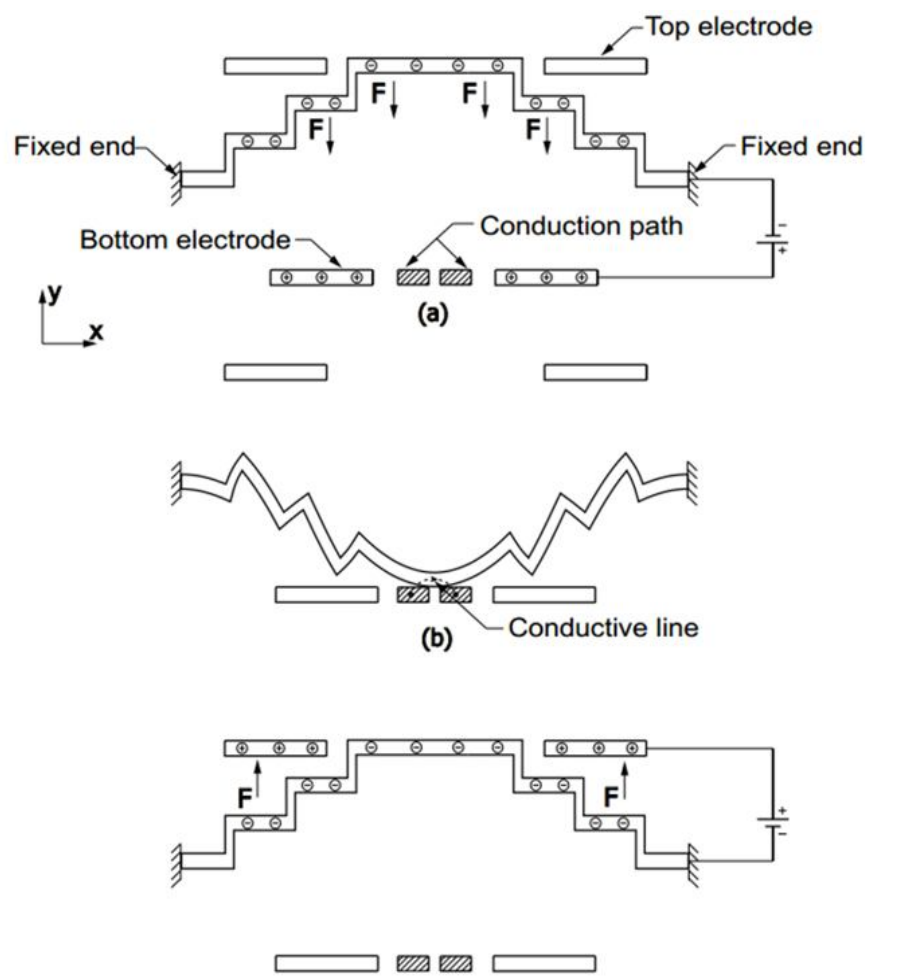

(c)

Figure 1: Schematic of a bistable switch at initial position (a); on state (b) and off state (c).

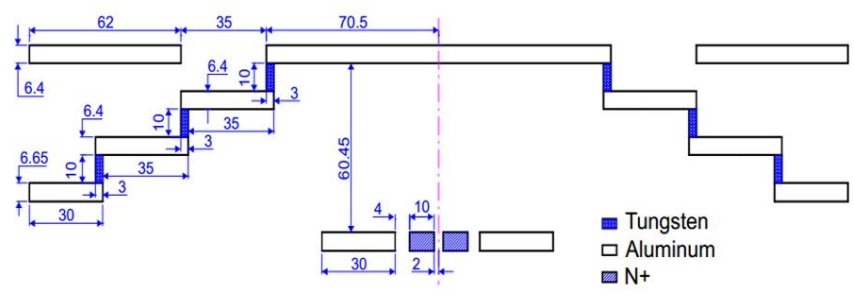

Figure 2: Dimensions of the bistable micro switch.

\section{MODEL}

Dimensions of the beam structure are indicates in Fig. 2. The lengths and thicknesses of the 4-layered structure are set based on the TSMC $2 \mathrm{P} 4 \mathrm{M}$ process. Based on the design rule of the process, the distance between the top electrode and the bottom electrode ( $\mathrm{N}+$ layer) is $60.45 \mu \mathrm{m}$. The width of the device is $2 \mu \mathrm{m}$.

Due to the nonlinear deformation of the beam structure, finite element analyses are employed to obtain the force and energy curves of the device. Fig. 3(a) shows a mesh for a two-dimensional finite element model.

A Cartesian coordinate system is also shown in Fig. 1(a). The finite element model has 9312 4-node elements. The CPE4R element type is employed in the analysis. The material properties are listed in Table 1.

The displacements in the $x$ and $y$ directions of the nodes at the anchors are constrained. A displacement in the $-y$ direction is applied to the nodes at the symmetric plane of the beam structure.

Table 1 Material properties of the device.

\begin{tabular}{|l|c|c|}
\hline & Aluminum & Tungtsen \\
\hline Young's modulus $(\mathrm{MPa})$ & $80 \times 103$ & $70 \times 103$ \\
\hline Poisson ratio $(-)$ & 0.35 & 0.35 \\
\hline Density $\left(\mathrm{g} / \mathrm{\mu m}^{3}\right)$ & $2.7 \times 10-12$ & $19.251-12$ \\
\hline Thickness $(\mu \mathrm{m})$ & 2 & 2 \\
\hline
\end{tabular}

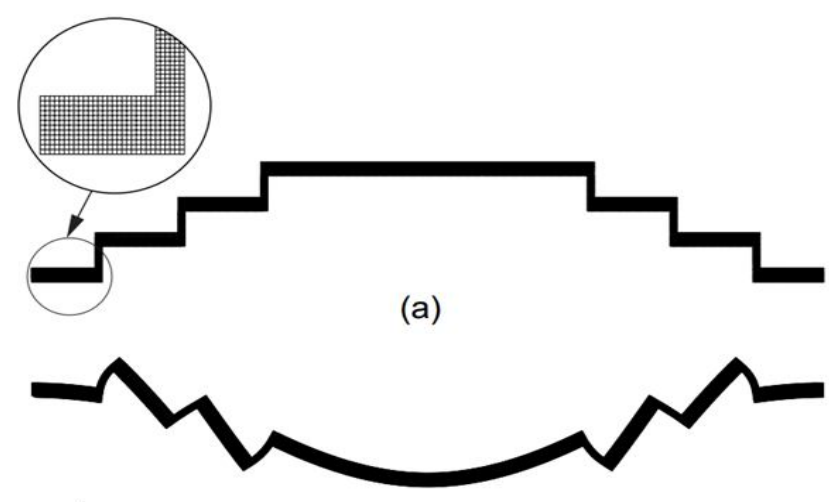

(b)

Figure 3: (a) Undeformed mesh and (b) deformed mesh of th e beam structure. 
Ngoc Tran Le et al., International Journal of Emerging Trends in Engineering Research, 8(10), October 2020, 6746 - 6749

\section{RESULTS AND DICUSSION}

Figure 3(b) shows a deformed mesh of the beam structure based on the finite element analyses. Figure 4 is the force-displacement (f-d) curve of the beam structure. The second stable equilibrium position occurs at a distance of $75.11 \mu \mathrm{m}$ from the first stable equilibrium position. The distance between the first stable equilibrium position and the unstable equilibrium position of the bistable structure, $60 \mu \mathrm{m}$, is less than the gap between the first stable equilibrium position and the conduction path, $60.45 \mu \mathrm{m}$, which is required to safeguard the bistable switch's contact with the conduction path. Figure 5 shows the stress - displacement curve of the device. The maximum stress is $6.9 \mathrm{GPa}$, layer is $60.45 \mu \mathrm{m}$. The width of the device is $2 \mu \mathrm{m}$.

Due to the nonlinear deformation of the beam structure, finite element analyses are employed to obtain the force and energy curves of the device. Figure 3(a) shows a mesh for a two-dimensional finite element model.

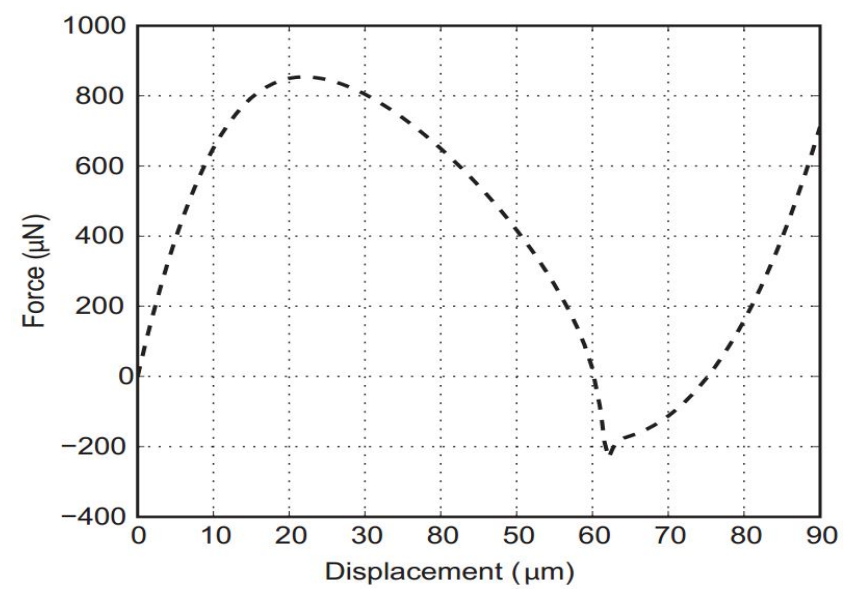

Fig. 4 F-d curve of the bistable switch.

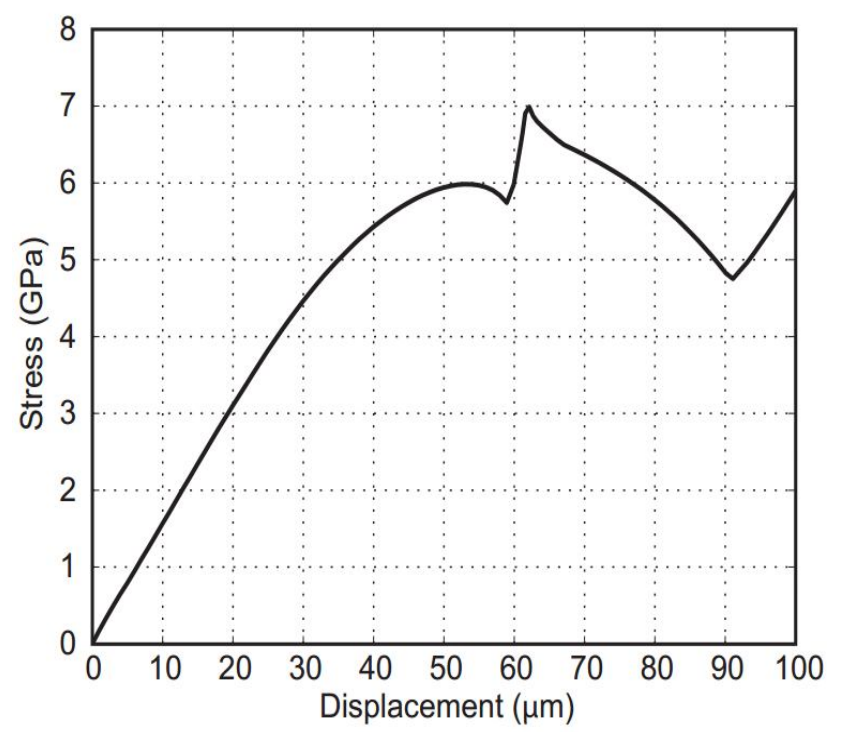

Fig. 5 Stress - displacement curve of the bistable switch.

\section{CONCLUSION}

A bistable switch based on a triple stepped beam is developed. The design of the beam structure follows the design rule of TSMC $2 \mathrm{P} 4 \mathrm{M}$ process. The $\mathrm{f}-\mathrm{d}$ curve of the device based on the finite element analyses guaranties reliable contact between the beam and the conduction path. A prototype is the device will be fabricated and tested to prove this design concept.

\section{REFERENCES}

1. G. E. Lancioni, M. F. O'Reilly, N. N. Singh, D. Olivia, M. M. Coppa and G. Montironi. A new microswitch to enable a boy with minimal motor behavior to control environmetal stimulation with eye blinks, Behavioral Interventions, vol. 20, issue 2, 2005.

2. J. Noetzel, T. Tønnesen, W. Benecke, J. Binder and G. Mader. Quasianalog accelerometer using microswitch array, Sensors and Actuators A: Physical, vol. 54, issue 1-3, pp. 574-578, 1996.

3. A. Delgado, E. L. Huamani and R. C. Salvatierra. Sensor Design to Measure the Ambient Temperature with Arduino and Raspberry Pi, International Journal of Emerging Trends in Engineering Research, vol. 8, no. 7, 2020.

4. A. A. Sokolovsky, A. I. Zemtsov, D. I. Kovalev, E. M. Shishkov and A. A. Kazantsev. Hybrid Fiber Optic Temperature Sensor Powered by Optical Radiation, International Journal of Emerging Trends in Engineering Research, vol. 7, no. 12, 2019.

5. L. Houlet, P. Helin, T. Bourouina, G. Reyne; E. Diffour-Gergam and H. Fujita, Movable vertical mirror arrays for optical microswitch matrixes and their electromagnetic actuation, IEEE Journal of Selected Topics in Quantum Electronics, vol. 8, issue 1 2002.

6. T. Hasegawa, K. Nakashima, F. Omatsu, K. Ikuta. Multi-directional micro-switching valve chip with rotary mechanism, Sensors and Actuators A: Physical, vol. 143, issue 2, pp. 390-398, 2008.

7. Z. Yang, G. Ding, W. Chen, S. Fu, X. Sun and X. Zhao, Design, simulation and characterization of an inertia microswitch fabricated by non-silicon surface micromachine, Journal of Micromechanics and Microengineering, vol. 17, no. 8, 2007.

8. Q. Xua, B. Sun, Y. Li, X. Xiang, L. Lai, J. Lia, G. Ding, $X$. Zhao and $Z$. Yang. Design and characterization of an inertial microswitch with synchronous follow-up flexible compliant electrodes capable of extending contact duration, Sensors and Actuators A: Physical, vol. 270, pp. 34-45, 2018.

9. W. H. Lin and Y. P. Zhao. Pull-in Instability of Micro-switch Actuators: Model Review, International Journal of Nonlinear Sciences and Numerical Simulation, vol. 9, no. 2, pp. 175-183, 2008. 
Ngoc Tran Le et al., International Journal of Emerging Trends in Engineering Research, 8(10), October 2020, 6746 - 6749

10. W. Chen, Y. Wang, Y. Zhang, P. Cheng, Y. Wang, G. Ding, X. Zhao and Z. Yang. Fabrication of a novel contact-enhanced horizontal sensitive inertial micro-switch with electroplating nickel, Microelectronic Engineering, vol. 127, no. 5, pp. 21-27, 2014.

11. A. Tommasi, G. Coletta, D. Balma, S. L. Marasso, D. Perrone, G. Canavese, S. Stassi, S. Bianco, M. Cocuzza and C. F. Pirri. Process optimisation of a MEMS based PZT actuated microswitch, Microelectronic Engineering, vol. 119, pp. 137-140, 2014.

12. X. Chen, C. H. J. Fox and S. Mcwiliam. Optimization of a cantilever microswitch with piezoelectric actuation, Journal of Intelligent Material Systems and Structures, vol. 15, issue 11, pp. 823-834, 2004.

13. S. Mao, H. Wang, Y. Wu, J. Tang and G. Ding. A latching bistable microswitch using dual-beam electrothermal actuation, IEEE 5th International Conference on Nano/Micro Engineered and Molecular Systems, China, 2010.

14. C. Castellana, F. Giazotto, M. Governale, F. Taddei, and F. Beltram. Superconductor-semiconductor magnetic microswitch, Applied Physics Letters, Volume 88, Issue 5, 2006.

15. S. Majumder, N. E. McGruer, G. G. Adams, P. M. Zavracky, R. H. Morrison and J. Krim. Study of contacts in an electrostatically actuated microswitch, Sensors and Actuators A: Physical, vol. 93, issue 1, pp. 19-26, 2001.

16. C. T. Jasmina and A. M. Shkel. Snap-action bistable micromechanism actuated by nonlinear resonance, Journal of Microelectromechanical Systems, vol. 17, pp. 893-896, 2005.

17. M. Vangbo and Y. Bäcklund, A lateral symmetrically bistable buckled beam, Journal of Micromech. Microeng., vol. 8, pp. 29-32, 1998.

18. B. D. Jensen, M. B. Parkinson, K. Kura K. Kurabayashi, L. L. Howell and M. S. Baker. Design optimization of a fully-compliant bistable micro-mechanism, Proceedings of the Technical Digest of 2001 ASME International Mechanical Engineering Congress and Exposition, NY, USA, pp. 1-7, 2001

19. J. Qui, J. H. Lang and A. H. Slocum. A centrally-clamped parallel-beam bistable MEMS mechanism, Proceedings of the IEEE Micro Electro Mechanical Systems (MEMS), pp. 353-356, 2001

20. M. Vangbo. An analytical analysis of a compressed bistable buckled beam, Journal of Sensors and Actuators, vol. 69, pp. 212-216, 1998.

21. W. B. Kim and S. Y. Han. Microinjection Molding of Out-of-Plane Bistable Mechanisms, Micromachines, vol. 11 , issue 2,2020

22. L. Zhou and H. Xie. A novel out-of-plane electrothermal bistable microactuator, Eurosensors XXXIII, Germany, 2019.

23. M. E. Khoury, C. Nakic, T. Winterstein and H. F. Schlaak. Electrothermal out-of-plane drive with novel bistable mechanism for portable Braille displays, MEMS, Shanghai, China, 2016.

24. K. Yu, A.Michael and C.Y. Kwok. Two- way bistable out-of-plane actuator using Ti/Sio2 Bilayer, Smart Structures, Devices, and Systems II, Vol. 5649, 2005.

25. X. Miao, X. Dai, Y. Huang, G. Ding and X. Zhao. Large Out-of-Plane Displacement Bistable Electromagnetic Microswitch on a Single Wafer, Sensors, vol. 16, issue $5,2016$. 